\title{
ЛЮБОВНЫЙ КОНФЛИКТ ГЕРОЕВ ХУДОЖЕСТВЕННОЙ ЛИТЕРАТУРЫ КАК ПРЕДМЕТ РИТОРИЧЕСКОГО АНАЛИЗА
}

\author{
Татьяна Лукьянова
}

\section{LOVE CONFLICT OF HEROES OF FICTION AS A SUBJECT OF RHETORICAL ANALYSIS}

\section{Tatyana Lukyanova}

\begin{abstract}
Резюме: В статье представлена характеристика любовного конфликта героев художественной литературы как коммуникативного феномена. Особое внимание уделяется приемам распознавания любовного конфликта в художественном тексте, а также жанровому репертуару конфликтного взаимодействия героев, связанных любовным общением.
\end{abstract}

Ключевые слова: любовный конфликт героев художественной литературы, жанры любовного конфликта.

\begin{abstract}
The article describes the love conflict of literary characters as a communicative phenomenon. Special attention is paid to the methods of recognizing love conflict in a literary text, as well as to the genre repertoire of conflict interaction between characters connected by love communication.
\end{abstract}

Key words: love conflict of heroes of fiction, genres of love conflict.

DOI: $10.14712 / 9788076032088.9$

Сегодня, как и во все времена, любовный конфликт является одним из самых распространенных коммуникативных явлений, так как участником любовного общения когдалибо становится каждый. Коммуниканты могут стать случайными наблюдателями за любовным конфликтом или его непосредственными «героями». При этом конфликтное любовное общение имеет сложную коммуникативную природу, в связи с чем анализ этого феномена с историкокультурной, психологической и речевой точек зрения смело можно назвать актуальной проблемой современности.

Многие авторы художественных текстов так же поднимают эту проблему в своих произведениях, показывая её через призму восприятия литературными персонажами. Однако обзор доступных нам научных работ (Анцупова 1999, Громовой 2000, Екимчик 2017, Панковой 1991, Ренц 2011, Скотта 1991, Сысенко 1989 и др.) показал, что любовным конфликтам героев художественных текстов с риторических позиций в науке должного внимания не уделяется. Также теоретический анализ научной литературы не позволил нам найти точного определения любовного конфликта, и мы пришли к выводу, что в современной науке есть множество нерешенных вопросов в данной области, особенно если эти вопросы касаются жанровой палитры конфликтного любовного взаимодействия, в том числе героев художественной литературы. 
При этом в работе О.А. Екимчик рассматриваются когнитивные и эмоциональные аспекты любовного общения, а в работе А. Я. Анцупова дается общее определение конфликта, который понимается как наиболее острый способ разрешения значимых противоречий, возникающих в процессе взаимодействия, заключающийся в противодействии субъектов конфликта и обычно сопровождающийся негативными эмоциями (Анцупов 1999). На основе полученных сведений в качестве объекта своей работы мы выбрали любовный конфликт (с опорой на семантику родового понятия), а ее предметом - любовный конфликт героев художественной литературы.

Опираясь на общеизвестное значение конфликта, с целью определить специфику понятия «любовный конфликт» мы обратились к характеристике феномена любви в разных исследованиях. Очевидным фактом является утверждение о том, что любовь - это сложное и многоаспектное явление, имеющее разные формы воплощения. Она не сводима к таким понятиям, как дружба и симпатия, однако основой развития любви могут быть именно эти чувства (Екимчик 2017). При этом любовь можно испытывать не только к объекту физических или платонических чувств, но и к своим близким, родным, друзьям. Зачастую это касается и любви к животным, к природе, личным увлечениям и интересам, занятиям любимым делом. Однако в аспекте нашего исследования под словом «любовь» мы будем понимать глубокое эмоциональное влечение или сильное сердечное чувство, возникающее между женщиной и мужчиной (Ожегов 1994).

Как известно, любовь в истории человечества проходит сложный путь эволюции и развития, она имеет культурно-историческую природу и представляет собой высшую форму человеческой близости, обеспечивающую оптимальные психологические условия для личностного развития и самореализации каждого из партнеров. На данный момент существует много классификаций развития любовных отношений, но для своего исследования мы выбрали теорию Л. М. Панковой, которая включает в содержание любовных отношений между мужчиной и женщиной три стадии:

1) привязанность, основанную на преданности, симпатии;

2) дифференциацию, т.е. первоначальное установление личных отношений между коммуникантами на основе усвоения культурных норм, правил и ценностей, что приводит к особым эмоциональным связям, изначально не предполагающим осознания личностью собственной самостоятельности;

3) индивидуализацию и автономизацию, когда обеспечивается достижение эмоциональной автономности, а личность осознает себя как целостность и индивидуальность, межличностные отношения строятся осознанно и произвольно, формируются зрелые вариации любви (Панкова 1991).

Отметим, что в какой бы стадии развития любовных отношений человек ни находился, он всегда имеет дело с общением со своим партнером. В данном случае возникает необходимость определить термин «любовное общение». Сегодня любовное общение не получило полного и детального описания в лингвистической литературе. Однако, основываясь на определении романтического общения у Т. Г. Ренц, мы самостоятельно сформулировали содержание данного понятия. Итак, под любовным общением мы понимаем интимноличностное взаимодействие, в основе которого лежит чувство любви между мужчиной и женщиной и которое может быть реализовано в самых разных формах вербального и действенного поведения любящих (Ренц 2011). Далее, опираясь на научную позицию В. В. Богданова, мы определили характерные особенности любовного общения. В их числе: высокая степень стремления быть в обществе любимого человека, осознание партнерами общности 
потребностей и целей, обмен значимыми мыслями и чувствами на основе веры в партнера, эмоциональность и эмоциогенность речи коммуникантов, что способствует обособлению одной любовной диады от другой (Богданов 1990). При этом в ситуациях любовного общения мужчины и женщины могут встречаться конфликты, на что зачастую влияют различные условия: обида одного партнера на другого, использование неискреннего речевого поведения кого-либо из партнеров, ревность в ситуациях с любовными треугольниками (и не только!), несовпадение интересов в конкретной, частной, ситуации, разность осознания таких понятий, как "долг», «честь», «измена», «предательство» и др.

Однако обзор доступных нам теоретических источников (Анцупова 1999, Громовой 2000, Екимчик 2017, Панковой 1991, Ренц 2011, Соловьева 2007) не позволил найти авторитетного определения термина «любовный конфликт», на основе чего мы пришли к выводу, что ученые практически не характеризуют его с коммуникативной точки зрения. При этом нередко исследователи трактуют данное понятие через явление «любовный треугольник», указывая на частотность возникновения конфликтов между любящими людьми по этой причине. Учитывая данные позиции, мы сформулировали рабочее определение любовного конфликта, под которым мы понимаем частную разновидность конфликта, возникающую между любящими людьми на основе ревности или неискреннего поведения партнеров, разногласий в понимании будущих семейных и настоящих межличностных отношений, разности в восприятии таких понятий, как честь, долг, преданность, искренность, забота, уважение и, в целом, любовь.

В связи с тем, что в рамках нашей работы мы особое внимание обращаем на любовный конфликт героев художественной литературы, мы обратились к определению и данного понятия. Опираясь на семантизацию конфликта в целом и любовного конфликта в частности, мы пришли к выводу, что любовный конфликт героев художественной литературы - это особое, созданное творческим воображением писателя взаимодействие двух любящих друг друга литературных персонажей с явно выраженной тематически негативной «окраской» их речевого поведения. В этом случае любовный конфликт является спроецированной, а не реальной моделью поведения героев, хотя в основе таких конфликтов зачастую лежит личный коммуникативный опыт мастера слова.

Следует также заметить, что любовный конфликт, реальный или художественно интерпретированный, можно узнать по: а) наличию в речи, голосе $и$ пантомимике коммуникантов жесткой, эмоционально не сдержанной интонации, резким жестам и активной, выражающей недовольство мимике, сопровождающей диалог любящих героев на важную для них обоих тему; б) особой системе речевых жанров любовного общения, носящих деструктивный характер воздействия на коммуниканта: требованиям, едким замечаниям, оскорбительным характеристикам, упрекам и т.д.); в) несдержанным действиям и поступкам коммуникантов, которые могут быть представлены как в ситуации непосредственного общения любящих людей, так и после завершения конфликтного разговора. В данном случае признаки распознавания любовного конфликта совпадают с типичными вариантами агрессивного поведения коммуникантов в ситуациях обычного конфликтного взаимодействия, однако главной отличительной чертой любовных конфликтов являются тематика общения и особенности взаимоотношений партнеров - любящих друг друга людей. А следовательно, их коммуникативные задача, а также языковое выражение типичных конфликтных речевых жанров будет так же отличным.

Как уже было отмечено, в силу частотности такого общения любовный конфликт довольно часто становится объектом пристального внимания известных мастеров слова, которые, 
применяя художественный вымысел, а также используя различные средства художественной выразительности, с целью особого эмоционального воздействия на читателей создают речевые образцы такого же конфликтного общения в своих произведениях. С помощью созданных ими сюжетных линий на страницах произведений художественной литературы появляются образы героев-любовников, участников художественно преобразованных любовных конфликтов. При этом любовные разногласия героев художественной литературы могут возникать на разных этапах их романтических отношений, в том числе после их завершения.

В качестве примера проанализируем ситуацию любовного конфликта из романа-эпопеи Л.Н. Толстого «Война и мир», где Наташа Ростова говорит Пьеру Безухову, что понимает, насколько сильно оскорбила и обидела Андрея Болконского, и просит, чтобы Пьер передал её возлюбленному искренние извинения и раскаяние в случившемся.

\section{Фрагмент №1}

- Нет, я знаю, что все кончено, - сказала она поспешно. - Нет, это не может быть никогда. Меня мучает только зло, которое я ему сделала. Скажите только ему, что я прошу его простить, простить, простить меня за все... - Она затряслась всем телом и села на стул (Толстой 2008).

В данном случае мы видим сбивчивую, эмоциональную, несдержанную речь героини, которая неоднократно, пусть и через третье лицо, просит у Андрея Болконского прощения, глубоко и искренне переживая произошедшее. Это доказывает поспешность ее речи, дрожь, пронизывающая все ее тело, жанровый репертуар ее спонтанных высказываний: упреков и замечаний в свой адрес, просьб, а скорее даже мольбы, о прощении. Обозначенный в данном диалоге «результат» отношений Наташи Ростовой и Андрея Болконского, содержание речи главной героини говорит о факте любовного конфликта между персонажами.

В следующем примере присутствует целый комплекс приемов (признаков), по которым так же можно распознать любовный конфликт.

\section{Фрагмент №2}

На ее щеках показался болезненный румянец.

Я продолжал: - Следственно, вы меня любить не можете...

Она отвернулась, облокотилась на стол, закрыла глаза рукою, и мне показалось, что в них блеснули слезы.

- Боже мой! - произнесла она едва внятно.

Это становилось невыносимо: еще минута, и я бы упал к ногам ее.

- Итак, вы сами видите, - сказал я, сколько мог, твердым голосом и с принужденной усмешкой, - вы сами видите, что я не могу на вас жениться, если б вы даже этого теперь хотели, то скоро бы раскаялись. Мой разговор с вашей матушкой принудил меня объясниться с вами так откровенно и так грубо; я надеюсь, что она в заблуждении: вам легко ее разуверить. Вы видите, я играю в ваших глазах самую жалкую и гадкую роль, и даже в этом признаюсь; вот все, что я могу для вас сделать. Какое бы вы дурное мнение обо мне ни имели, я ему покоряюсь... Видите ли, я перед вами низок. Не правда ли, если даже вы меня и любили, то с этой минуты презираете?

Она обернулась ко мне бледная, как мрамор, только глаза ее чудесно сверкали.

- Я вас ненавижу... - сказала она (Лермонтов 2014).

В данной ситуации общения героиня потрясена заявлением Григория о том, что всё его внимание к ней было шуткой. Она оскорблена, и вся её боль, ненависть отражаются сначала в мимике, позе, взгляде («болезненный румянец», «отвернулась», «закрыла глаза рукою», 
«произнесла она едва внятно», «бледная, как мрамор», «глаза ее сверкали»), а лишь затем и в словах («Я вас ненавижу»). При этом провоцирующими конфликтную реакцию героини становятся и речевые действия самого героя. Во-первых, он говорит с усмешкой, во-вторых, он признается ей в том, что не может на ней жениться, что вынужден говорить с ней грубо, однако, пытаясь себя оправдать, он снисходительно позволяет ей составить о нем дурное мнение.

Выделенные в двух примерах конструкции указывают на ритмико-интонационные, пантомимические и вербальные признаки выражения любовного конфликта, в связи с чем признаки, по содержанию которых можно узнать любовный конфликт, мы назвали приемами его распознавания. При этом отметим, что главным приемом узнавания такого конфликта является содержание речи героев, облаченное в относительно устойчивые по композиции, наполнению и языковому выражению высказывания, получившие название речевых жанров (Бахтин 1996).

Помимо М.М. Бахтина, проблемой изучения речевых жанров занимались В. В. Дементьев, А. Е. Земская, Т. В. Шмелева и мн. др. Из всего многообразия исследованных высказываний к жанрам любовного конфликта мы отнесли: насмешку, обвинение, обещание, оправдание, извинение, комплимент, просьбу, требование, угрозу, упрёк, утешение, ссору и некоторые др. Отметим, однако, что жанровое своеобразие любовного конфликта не заканчивается перечисленными высказываниями: мы назвали лишь самые частотные из них.

Опираясь на классификацию А.Я. Анцупова, все жанры любовного конфликта мы поделили на два типа: конструктивные, которые приводят к продуктивным, взаимовыгодным и согласованным решениям, и деструктивные, которые способствуют неблагоприятному разрешению конфликта, а именно: разрыву отношений (Анцупов 1999).

На основе анализа реальной и художественно интерпретированной практики к деструктивным жанрам любовного конфликта мы отнесли следующие.

Упрёк - речевой жанр, в котором выражено неудовольствие, неодобрение кого-либо по отношению к другому участнику коммуникации.

Подробно рассмотрим этот жанр на примере общения Настасьи Филипповны и князя Мышкина, который упрекает её за недостойное поведение в доме Иволгиных (роман Ф.М. Достоевского «Идиот»).

\section{Фрагмент №3}

- А вам и не стыдно! Разве вы такая, какою теперь представлялись. Да может ли это быть! - вскрикнул вдруг князь с глубоким сердечным укором.

Настасья Филипповна удивилась, усмехнулась, но, как будто что-то пряча под свою улыбку, несколько смешавшись, взглянула на Ганю и пошла из гостиной (Достоевский 2010).

Как видно из данного примера, упрек в любовной коммуникации (на разных стадиях ее развития и осознания) может выражаться с усмешкой, с сарказмом, а может содержать и испуг. Все зависит от цели упрека - обидеть человека или дать напутствие, выразить неодобрение поведения коммуниканта или косвенно признать свою вину, резко обозначив свою ответную реакцию как вид эмоциональной защиты.

Обвинение - речевой жанр, в котором коммуниканту приписывается вина за совершенное им действие, содержание которого отрицательно оценивается партнером по любовному общению. Приведем пример.

\section{Фрагмент №4}

- Ты, ты виноват во всем! - вскрикнула она со слезами отчаяния и злости в голосе, вставая (Толстой 2013). 
В данном случае главная героиня - Анна Каренина - гиперболизирует вину своего возлюбленного - Вронского. Зачастую женскому стилю поведения, основанному на глубоких и искренних эмоциях, присуща такая стилевая черта, особенно если речь идет о любовной коммуникации.

Оскорбление / негативная оценочная характеристика - любое слово или выражение, содержащее обидную характеристику адресата. При этом слово может быть употреблено как в прямом, так и в переносном значениях. Приведем пример.

\section{Фрагмент №5}

Татьяна вспыхивает:

- Тебе домработница нужна, а не жена! - Она вскакивает с кровати, поправляет на себе халат. - Я ухожу к маме! Ты меня достал! я не буду за тебя выходить замуж, зануда!

- Прощай, ленивая кобыла. Несчастным будет тот, кто на тебе женится.

- Ну, ты подлец! (Леконт 2001).

Причина данного конфликта - нежелание девушки выполнять домашние обязанности. В этом ее упрекает жених. В данном случае оба героя используют в своей речи оскорбления, т.е. слова с ярко выраженной негативной экспрессивной окраской.

Представив краткий обзор деструктивных жанров художественной любовной коммуникации в конфликтном варианте ее проявления, обратимся к конструктивным жанрам любовного конфликта, к которым зачастую относятся высказывания этикетного характера. Приведем примеры.

Извинение - речевой жанр, в котором содержится просьба о прощении. Данное высказывание является одним из самых эффективных при любовном конфликте. Чаще всего извиняется тот партнер, который начал конфликт, то есть инициатор. Однако бывают и обратные ситуации. В качестве примера использования жанра приведем фрагмент из пьесы А.Н. Островского «Гроза»: Тихон Кабанов собирается уехать из дома, а Катерина, его жена, предчувствуя беду, не хочет отпускать его одного.

\section{Фрагмент №6}

Кабанов. Катя!

Молчание.

-Катя, ты на меня не сердишься?

Катерина (после непродолжительного молчания, качает головой). Hет!

Кабанов. Да что ты такая? Ну, прости меня! (Островский 2014).

Извинение чаще всего следует за объяснением, в ходе которого проясняется конфликтная ситуация, и партнер, который был неправ, стараясь искупить свою вину, произносит извинительную речь. Однако коммуникативные задачи таких высказываний могут быть самыми разными в зависимости от условий конкретной речевой ситуации.

Утешение - речевой жанр, в котором, напротив, высказываются слова лишь искреннего сочувствия, сопереживания. Этот жанр в большей степени в ситуациях любовного конфликта адресован женщинам, так как они часто нуждаются в эмоциональной поддержке, однако и мужчинам - героям художественной литературы - этот жанр может быть адресован нередко. В качестве иллюстрации использования данного высказывания приведем пример, где герои, расставшись несколько лет назад, вновь встречаются. При этом героиня обвиняет партнера в том, что он ее когда-то покинул, а мужчина утешает свою возлюбленную.

Фрагмент №7 
ОН. Бедная моя девочка. Совсем запуталась. Половинки - серединки. Всё хорошо, Машенька. Всё будет хорошо, девочка моя (Богачева 2002).

Обещание - речевой жанр, в котором высказывается обязательство, уверение в том, что что-либо будет сделано, исполнено, дано. При использовании этого жанра один партнер уступает другому или оба предпринимают взаимные уступки. В любом случае партнеры чаще всего этим и завершают любовный конфликт.

В представленной ниже ситуации главный герой объясняет возлюбленной, что ему нужно уехать и то, почему он не может взять ее с собой.

\section{Фрагмент №8}

- У меня нет дома, Таня, я всю жизнь езжу с места на место... В Москве живу в номерах... И ни на ком никогда не женюсь...

- Отчего?

- Оттого, что уж такой я родился.

- И ни на ком никогда не женитесь?

- Ни на ком, никогда! И даю тебе честное слово, мне, ей-богу, необходимо, очень важные и неотложные дела. К Рождеству непременно приеду! (Бунин 2012, рассказ «Таня»).

В данном случае герой дает два обещания: во-первых, не жениться и, во-вторых, приехать на Рождество. При этом он использует такие клишированные фразы и слова, как «Никогда...», "Даю тебе честное слово», "Непременно...».

Подводя промежуточный итог, отметим следующее:

1. Охарактеризованные речевые жанры, выявленные нами на основе анализа фрагментов из художественных текстов о любви, зачастую сопровождаются особыми голосовыми и пантомимическими признаками. Например, в ситуации использования конструктивных жанров герои обращаются к искренней, ласковой, проникновенной интонации; умеренному ритму и темпу речи; открытым жестам, улыбке, возможности близкого контакта с партнером (подержать руку собеседника, обнять его (ее), погладить по плечу) и т.д.. Для деструктивных жанров характерны: повышение тона, жесткость и резкость голоса или, наоборот, вялость и выражение скуки; жесты чаще всего резкие, порывистые; между собеседниками часто возникает большое расстояние, телесного контакта нет; на лице возможна язвительная усмешка.

2. Жанровый репертуар любовного конфликта многообразен, и самые типичные ситуации использования высказываний, сопровождающих такой конфликт, можно найти в разных произведениях художественной литературы, которая зачастую является не только образцом этикетного использования деструктивных и конструктивных жанров любовного общения (особенно если речь идет о классической литературе), но и образцом различных приемов нейтрализации конфликта любящих друг друга героев.

В связи с этим следующим аспектом нашей статьи стал анализ так называемых приемов нейтрализации конфликтного любовного взаимодействия литературных персонажей. Приведём пример из рассказа А. П. Чехова «О любви».

\section{Фрагмент №9}

...нужно было проститься. Когда тут, в купе, взгляды наши встретились, душевные силы оставили нас обоих, я обнял ее, она прижалась лицом к моей груди, и слезы потекли из глаз; целуя ее личо, плечи, руки, мокрые от слез, - о, как мы были с ней несчастны! - я признался ей в своей любви, и со жгучей болью в сердие я понял, как не нужно, мелко и как обманчиво было все то, что нам мешало любить (Чехов 2012). 
В данном фрагменте приёмом нейтрализации возможного любовного конфликта стали искренние объятия героев, с помощью которых Алёхин смог хотя бы на время уладить любовные разногласия с Анной. При этом мы признаем контекстуальную «ограниченность» данного фрагмента и, с учетом описанного А.П. Чеховым финала, понимаем неизбежность разрыва возлюбленных. С точки зрения литературоведческого анализа данного рассказа, стоит актуализировать факт о том, что он входил в знаменитую «футлярную» трилогию писателя, и главные герои этой истории в силу разности представлений о возможном будущем, собственных страхов и опасений не разрешили себе продолжить любовное общение. В результате, их встречи закончились трагически для обоих, - завершением возможных счастливых отношений, что также иллюстрирует наличие любовного конфликта, но уже на финальном этапе развития любовной коммуникации.

В следующем примере герои романа-эпопеи Л. Н. Толстого «Война и мир» из конфликта выходят с помощью таких вербальных приёмов нейтрализации, как просьба о прощении и признание вины.

\section{Фрагмент №10}

-Простите меня за то, что я сделала,-чуть слышным, прерывным шепотом проговорила Наташа и чаще стала, чуть дотрагиваясь губами, целовать руку.

- Я люблю тебя больше, лучше, чем прежде, - сказал князь Андрей, поднимая рукой ее лицо так, чтобы он мог глядеть в ее глаза (Толстой 2008).

Отметим, что мы привели далеко не полный перечень речевых и действенных (на уровне поступков) приемов, с помощью которых можно нейтрализовать, т.е. «свести на нет», любовный конфликт, однако самый главный вывод, к которому мы пришли, заключается в том, что именно конструктивные речевые жанры любовного общения могут стать одними из таких приемов. При этом уместность и этикетность их использования в образцах художественной литературы может стать своеобразным «напутствием» для современников - участников реальных любовных конфликтов.

Завершая размышления о конфликтном любовном общении героев художественной литературы, подведем некоторые итоги. Во-первых, любовный конфликт относится к одной из самых распространённых разновидностей проблемной коммуникации. Именно поэтому данный феномен по сей день является самым обсуждаемым в современной науке и реальной речевой практике. В силу частности такого общения любовный конфликт становится объектом пристального внимания и известных мастеров слова, которые, применяя художественный вымысел и используя различные средства художественной выразительности, создают аспектные речевые образцы.

Во-вторых, любовный конфликт как коммуникативное явление детально не рассматривается в конфликтологии, психолингвистике и лингвистике, в связи с чем в рамках своей работы мы самостоятельно сформулировали значение любовного конфликта и определили семантику любовного конфликта героев художественной литературы. На основе обзора различных речеведческих источников, а также на основе анализа художественных образцов мы выявили базовый жанровый репертуар конфликтного любовного общения, выделив в числе частотных жанров ссоры, упреки, замечания, требования, необоснованные или уместные обвинения, извинения, просьбы о прощении и т.д., а также обозначили основные приемы распознавания такого взаимодействия и приемы его нейтрализации, смягчения. Отметим, что на основе детального риторического анализа художественных образцов, содержанием которых становится любовный конфликт, можно определить возможные тактики 
успешного речевого поведения возлюбленных в реальных ситуациях конфликтного общения. Это утверждение в очередной раз доказывает общеизвестный факт, что классическая художественная литература до сих пор является для современных читателей “уроком жизни», авторитетность которого не вызывает сомнений.

\section{Использованная литература/ References}

\section{Печатные источники:}

АНЦУПОВ, А. Я. (1999): Конфликтология : учеб. для студентов вузов. Москва : ЮНИТИ, 1999. 591 с. ISBN 5238-00062-6.

БАХТИН, М. М. (1996): Проблема речевых жанров : сборник научных трудов. Москва: Русские словари, 1996. ISSN 2227-8397.

БОГДАНОВ, В. В. (1990): Речевое общение: прагматические и семантические аспекты : учебное пособие. Ленинград : Ленин, 1990. 88 с.

БУНИН, И. А. (2012) : Темные аллеи. Ростов-на-Дону : Феникс, 2012. 286 с. ISBN 978-5-222-18497-4.

ГРОМОВА, О. Н. (2000): Конфликтология : курс лекций. Москва : ЭКМОС, 2000. 318 с. ISBN 5-88124-042-1.

ДЕМЕНТЬEВ, В. В. (2007) : Изучение речевых жанров в России: аспект формализации социального взаимодействия. Москва : Лабиринт, 2007. 61 с. ISBN 5-87604-190-4.

ДОСТОЕВСКИЙ, Ф. М. (1010) : Идиот : роман. Москва : АСТ МОСКВА, 2010. 621 с.

ЕКИМчИК, О. А. (2017): Психология любви в отношениях мужчины и женщины: методы психологической диагностики : методическое руководство. Кострома : КГУ, 2017. 71 с. ISBN 978-5-8275-0859-4.

ЗЕМСКАЯ, Е. А. (2004) :Русская разговорная речь : лингвистический анализ и проблемы обучения : учебное пособие. Москва : Наука, 2004. 239 с. ISBN 5-89349-635-3.

ЛЕРКОНТОВ, М. Ю . (2014) : Герой нашего времени : роман. Санкт-Петербург : Лениздат, 2014. 222 с. ISBN 978-5-4453-0462-3.

Общение-компетентность-тренинг: избранные труды / под ред. О. В. Соловьева. Москва : Смысл, 2007. $691 \mathrm{c}$.

ОЖЕГОВ, С. И. (1994): Толковый словарь русского языка. Москва : Азъ, 1994. 907с. ISBN 5-85632-007-7.

ОСтРОВСКИЙ, А. Н. (2014) : Гроза : пьесы. Санкт-Петербург : Лениздат, 2014. 348 с. ISBN 978-5-4453-04869.

ПАНКОВА, Л. М. (1991) : У порога семейной жизни : книга для учителя. Москва : Просвещение, 1991. 143 c. ISBN 5-09-002994-6.

Психология семейных отношений с основами семейного консультирования : учебное пособие / под ред. Е. Г. Силяевой. Москва : Академия, 2005. 192 с. ISBN 5-7695-1745-X.

РЕНЦ, Т. Г. (2011) : Романтическое общение в коммуникативно-семиотической парадигме : монография. Волгоград : ВолГУ, 2011. 382 с. ISBN 978-5-9669-0930-7.

СКОТТ, Дж. Г. (1991): Конфликты, пути их преодоления. Киев : Внешторгиздат, 1991. 191 с. ISBN: 5-8502505-7.

Социальная конфликтология : учеб. пособие для студентов вузов: под ред. А. В. Морозова. Москва : Academia, 2002. 332 c. ISBN 5-7695-0845-0.

СЫСЕНКО, В. А. (1989) : Супружеские конфликты. Москва : Мысль, 1989. 173 с. ISBN 5-244-00297-Х.

толстой, Л. Н. (2013) : Анна Каренина : роман. Санкт-Петербург : Азбука, 2013. 861 с. ISBN 978-5-38904935-2.

толстой, л. Н. (2008) : Война и мир : роман в четырех томах. Москва : Эксмо, 2008. 736 с. ISBN 5-69913660-6.

ЧЕХОВ, А. (2012) : О любви : рассказы. Санкт-Петербург : Азбука-Аттикус, 2012. 381 с. ISBN 978-5-389-031012.

ШМЕЛЕВА, Т. В. (1997) : Модель речевого жанра. Саратов : Гос, 1997. 98 с. ISBN 5-900641-49-X. 


\section{Онлайн-источники:}

БОГАЧЕВА, А. (2002) : За стеклянными дверями. 2002. Текст электронный. URL: www.newdrama.ru (дата обращения: 15.02.2020).

ЛЕКОНT, В. (2001): Свадебный «подарок». Текст : электронный. URL: www.newdrama.ru. (дата обращения: 25.02.2020).

НОВИКОВА, Т. Ф. (2018): Приёмы нейтрализации вербальной агрессии в составе средств речевого воздействия. 2018. Текст электронный. URL: https:// cyberleninka.ru/article/n/priemy-neytralizatsiiverbalnoy-agressii-v-sostave-sredstv-rechevogo-vozdeystviya [дата обращения: 08.12.2019].

\section{Профиль автора:}

Татьяна Лукьянова, студентка 3 курса факультета филологии Новокузнецкого института (филиала) ФГБОУ ВО «Кемеровский государственный университет»

Научный руководитель: Любовь Викторовна Гордеева, кандидат педагогических наук, доцент

Научные интересы: коммуникативная культура педагога-филолога, речевая практика современников, жанры речи, теория и методика обучения русскому языку и литературе, школьное и вузовское филологическое образование.

e-mail: lyuba.gordeeva.85@mail.ru

Место работы: Новокузнецкий институт (филиал) ФГБОУ ВО «Кемеровский государственный университет», факультет филологии, кафедра русского языка и литературы; г. Новокузнецк, ул. Радищева, д. 34, кв. 21, индекс: 654086, Россия.

\section{Author's profile}

Tatyana Lukyanova, 3rd year student of the faculty of Philology of Novokuznetsk Institute (branch) Kemerovo state University

Scientific supervisor: Lyubov Viktorovna Gordeeva, candidate of pedagogical Sciences, associate Professor Research interests: communicative culture of a philologist, speech practice of contemporaries, genres of speech, theory and methods of teaching Russian language and literature, school and University philological education. e-mail: lyuba.gordeeva.85@mail.ru

Place of work: Novokuznetsk Institute (branch) Kemerovo state University, faculty of Philology, Department of Russian language and literature; Novokuznetsk, 34 Radishcheva str., sq. 21, index: 654086, Russia. 